\title{
Retirement of John Dover as Editor-in-Chief of Journal of Insect Conservation
}

\author{
James Stephen Pryke ${ }^{1} \cdot J_{0 r g e}$ L. León-Cortés ${ }^{2} \cdot$ Dirk Maes $^{3}$
}

Published online: 2 November 2017

(C) Springer International Publishing AG 2017

With the retirement of Professor John Dover as Editor-inChief, this issue marks the end of an important era for the Journal of Insect Conservation. John has a long career working on insect conservation, especially on the conservation of butterflies and their habitats. In 1983, John received his Ph.D. on "The effects of non-host plants on the ecology of Brassica Lepidoptera" at Southampton University and since then he has published over 60 scientific papers. Apart from scientific writing, John has spent a great deal of time encouraging many young biologists to take an interest in insect conservation and (agricultural) landscape ecology.

Beyond academia, John has also helped to set up the green infrastructure within the urban and agri-environments in many applied schemes that have enhanced insect diversity in Staffordshire. This implementation of academic theory in the real world is an important step that not many academics take and John should be applauded for this achievement.

In January 2009, John joined the Journal of Insect Conservation editorial board and in 2014, he took over as Editor-in-Chief. One of John's major achievements was the

Dirk Maes

dirk.maes@inbo.be

James Stephen Pryke

jpryke@sun.ac.za

Jorge L. León-Cortés

jleon@ecosur.mx

1 Conservation Ecology and Entomology, Stellenbosch University, Private Bag X1, Matieland, Western Cape 7602, South Africa

2 Departamento de Conservación de la Biodiversidad, El Colegio de la Frontera Sur, Carr. Panamericana y Periférico Sur S/N, 29290 San Cristóbal de las Casas, Chiapas, Mexico

3 Species Diversity Group, Research Institute for Nature and Forest (INBO), Kliniekstraat 25, 1070 Brussels, Belgium modernisation of the journal's editorial system: an Editor-inChief supported by a number of Associate Editors selecting reviewers and making recommendations on manuscripts following completion of the reviews. John managed to expand the number of Associated Editors to 20, which permitted the journal to handle the ever-growing number of submissions. In John's words, “...it is really great to feel that you are helping with the scientific process and, in many cases, helping people getting published. Sometimes it can seem that the role of a journal is to obstruct publication (at least to rejected authors), but I firmly believe that at the Journal of Insect Conservation we have managed to help authors rather than hinder them...". The new Editor-in-Chief team remains highly-committed to continue John's approach to publication, by assisting researchers in getting papers on insect conservation published.

When John decided to retire as Editor-in-Chief, he thought that it would be better to spread the increasing workload of a modern academic journal over a team of three Co-Editors-in-Chief. One of the main challenges for the new Editor-in-Chief team will be to increase the impact factor of the journal. In striving for this objective, we are committed to provide support for prospective authors in publishing high quality papers in a journal tailored to their needs and interests.

We would like to thank John for his hard work for the Journal of Insect Conservation and for his confidence in us as the new team of Editors-in-Chief. We can now appreciate the amount of work he has has to do on a day-to-day basis and the journal owes him a huge debt. It was a pleasure working with John and we wish him well and much enjoyment in his retirement. 